\title{
$\begin{array}{ll}\text { Research Square } & \text { Preprints are preliminary reports that have not undergone peer review. } \\ \text { They should not be considered conclusive, used to inform clinical practice, }\end{array}$ or referenced by the media as validated information. \\ Excellent Energy Storage Performance in $\mathrm{NaNbO}_{3}-$ Based Relaxor Antiferroelectric Ceramics Under a Low Electric Field
}

\section{Xuxin Cheng}

Zhaoqing University

Pengyuan Fan ( $\nabla$ pyfan@hust.edu.cn )

Huazhong University of Science and Technology - Main Campus: Huazhong University of Science and Technology https://orcid.org/0000-0001-6192-7828

\section{Xiaoming Chen}

Zhaoqing University

\section{Research Article}

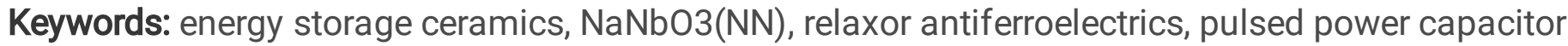

Posted Date: August 24th, 2021

DOI: https://doi.org/10.21203/rs.3.rs-812278/v1

License: (c) (i) This work is licensed under a Creative Commons Attribution 4.0 International License. Read Full License 


\section{Abstract}

$\mathrm{NaNbO}_{3}$-based antiferroelectric (AFE) ceramics have the prominent advantages of stable performance and low cost. However, its energy storage property is often remarkably limited by the hysteresis of the antiferroelectric to ferroelectric phase transformation. In this work, $0.88 \mathrm{Na}\left(\mathrm{Nb}_{1-x} \mathrm{Ta}_{x}\right) \mathrm{O}_{3}-$ $0.12 \mathrm{Bi}_{0.2} \mathrm{Sr}_{0.7} \mathrm{TiO}_{3}(x=0-0.075)$ antiferroelectric ceramics were synthesized using a conventional mixed oxide route. $\mathrm{Ta}^{5+}$ were completely dissolved into the lattice of $0.88 \mathrm{NaNbO}_{3}-0.12 \mathrm{Bi}_{0.2} \mathrm{Sr}_{0.7} \mathrm{TiO}_{3}$ to form a pure perovskite structure. With increased Ta content, the AFE orthogonal P phase was replaced by AFE orthogonal R phase progressively. Meanwhile, the dielectric constant curve showed relaxor-like properties. As a result, slender $P-E$ curves with reduced hysteresis loss and decreased residual polarization were achieved. Interestingly, a large recoverable energy storage density $\left(W_{\text {rec }} \approx 2.16 \mathrm{~J} \mathrm{~cm}^{-3}\right)$ and high energy storage efficiency $(\eta \approx 80.7 \%$ ) were obtained simultaneously under a low driving electric field of $15 \mathrm{kV}$ $\mathrm{mm}^{-1}$ at doping ratio $(x)$ of 0.075 . In addition, the $0.88 \mathrm{Na}\left(\mathrm{Nb}_{0.925} \mathrm{Ta}_{0.075}\right) \mathrm{O}_{3}-0.12 \mathrm{Bi}_{0.2} \mathrm{Sr}_{0.7} \mathrm{TiO}_{3}$ sample exhibited excellent temperature stability, indicating an ideal candidate in future pulsed power capacitor.

\section{Introduction}

Dielectric energy storage capacitors have fast charging and discharging rates ( ns) and higher power density (exceed $10^{8} \mathrm{~W} \mathrm{~kg}^{-1}$ ) [1-4]. These capacitors are important components of pulse power electronic systems and are widely used in various fields, such as electromagnetic ejection, electromagnetic gun, electric vehicle, medical defibrillator, smart grid, spacecraft, and satellite [5-8]. The materials used in dielectric energy storage capacitors include organic and ceramic materials. Compared with organic and electromechanical materials, ceramic materials have higher dielectric constant $\left(\varepsilon_{r}\right)$ and can maintain stable energy storage characteristics at temperatures higher than $200^{\circ} \mathrm{C}$ [9-11]. At present, the research on energy storage dielectric ceramics focuses on four categories, i.e., linear dielectric (such as $\mathrm{TiO}_{2}$ and $\mathrm{SrTiO}_{3}$ ) [12, 13], normal ferroelectric (FE; such as $\mathrm{K}_{0.5} \mathrm{~N}_{0.5} \mathrm{NbO}_{3}, \mathrm{BaTiO}_{3}$, and $\mathrm{BiFeO}_{3}$ ) [14-16], relaxor ferroelectric (RFE; such as $\mathrm{Na}_{0.5} \mathrm{Bi}_{0.5} \mathrm{TiO}_{3}$-based) [17-20], and antiferroelectric (AFE; such as PLZST, $\mathrm{AgNbO}_{3}$, and $\mathrm{NaNbO}_{3}$ ) ceramics [21-32]. FE ceramics have low $W_{\text {rec }}$ and $\eta$ because of high residual polarization $\left(P_{\mathrm{r}}\right)$. Linear dielectric ceramics often have low $\varepsilon_{n}$ causing a low $W_{\text {rec }}$. Because the breakdown field strength $\left(E_{\mathrm{b}}\right)$ of RFE ceramics is low, it has low $W_{\text {rec }}$. AFE ceramics have high maximum polarization $\left(P_{\mathrm{m}}\right)$ due to the existence of AFE-FE phase transition, resulting in high $W_{\text {rec }}$. However, its inherent AFE-FE phase transition causes large hysteresis loop, resulting in large energy loss. A high $W_{\text {rec }}$ and $\eta$ are difficult to obtain simultaneously in AFE ceramics, which has become a key problem restricting its energy storage application $[24,28,33]$.

The lead-free AFE material in high-power capacitors is attracting a growing body of research because of its advantages of high energy and high power density. It has become one of the most popular and promising research directions. Compared with PLZST and $\mathrm{AgNbO}_{3}$-based AFE ceramics, $\mathrm{NaNbO}_{3}(\mathrm{NN})$ based AFE ceramics have many advantages, such as nontoxicity, stable performance, and low cost [34- 
36]. At room temperature (RT), NN exhibits AFE orthorhombic P phase, and it turns into AFE orthorhombic $R$ phase at about $360^{\circ} \mathrm{C}$ [37]. However, the AFE $P$ phase in undoped modified $\mathrm{NaNbO}_{3}$-based ceramics is unstable and easily transformed into the orthorhombic FE phase, resulting in an irreversible AFE-FE phase transition and displaying a square $P$ - $E$ loop similar to that of FE materials [35, 36], thus decreasing its $\eta$. The two aspects in the current research on the modification of $\mathrm{NaNbO}_{3}$-based AFE ceramics are as follows. 1) A stable AFE $P$ phase can be obtained by doping $\mathrm{BaZrO}_{3}, \mathrm{CaZrO}_{3}, \mathrm{CaSnO}_{3}$, and other perovskite structural materials [34-38], which can stabilize the AFE P phase under RT, realize reversible AFE-FE phase transition, and obtain typical AFE double-hysteresis loop (beam waist type). This phenomenon can improve the $W_{\text {rec }}$ and $\eta$ of materials, which are only $3 \mathrm{~J} \mathrm{~cm}^{-3}$ and $74 \%$, respectively. 2) The stable antiferroelectric $\mathrm{R}$ phase under $\mathrm{RT}$ can be obtained by introducing $12 \mathrm{~mol} \% \mathrm{Bi}_{0.5} \mathrm{Na}_{0.5} \mathrm{TiO}_{3}$ into $\mathrm{NaNbO}_{3}$-based AFE phase, It has a thinner hysteresis loop than the antiferroelectric $\mathrm{P}$ phase can be obtained under RT. Thus a high $W_{\text {rec }}$ of $12.2 \mathrm{~J} \mathrm{~cm}^{-3}$ and a acceptable $\eta$ of $69 \%$ were achieved[38, 39].

Ta has been displayed to be a high-quality dopant in $\mathrm{AgNbO}_{3}$ for improving the AFE phase stability [2628]. For example, $15 \mathrm{~mol} . \%$ Ta doping in $\mathrm{AgNbO}_{3}$ can enhance $E_{\mathrm{b}}$ by nearly $23 \mathrm{kV} \mathrm{mm}^{-1}$, thus obtaining a large recoverable energy storage density of $4.2 \mathrm{~J} \mathrm{~cm}^{-3}$ and increased $\eta$ of $69 \%$. Results show that the antiferroelectricity can be enhanced by replacing $\mathrm{Nb}$ with Ta due to decreased polarizability of B-site cations in distorted AFE configuration. In addition, the addition of Ta can increase the bulk density and reduce the grain size of $\mathrm{AgNbO}_{3}$ ceramics, thus remarkably improving the $E_{\mathrm{b}}$ of materials [26]. However, research on Ta doping in NN-based system with stable AFE P phase is lacking. This finding is a good example to show that NN is different from other AFE perovskite systems in nature.

In this paper, a new type of lead-free $0.88 \mathrm{Na}\left(\mathrm{Nb}_{1-x} \mathrm{Ta}_{x}\right) \mathrm{O}_{3}-0.12 \mathrm{Sr}_{0.7} \mathrm{Bi}_{0.2} \mathrm{TiO}_{3}$ solid solution ceramics is fabricated using a traditional solid-state reaction technique. The relationships of structure with ferroelectric, dielectric and energy storage performance are systematically investigated. The phase transition from the AFE P phase to AFE R phase caused by Ta doping contributes to enhanced energy storage performance. As a result, a large $W_{\text {rec }}$ of $2.16 \mathrm{~J} \mathrm{~cm}^{-3}$ and a high $\eta$ of $80.7 \%$ under $15 \mathrm{kV} \mathrm{mm}^{-1}$ are obtained in the $0.88 \mathrm{Na}\left(\mathrm{Nb}_{0.925} \mathrm{Ta}_{0.075}\right) \mathrm{O}_{3}-0.12 \mathrm{Bi}_{0.2} \mathrm{Sr}_{0.7} \mathrm{TiO}_{3}(\mathrm{NN}-\mathrm{BST}-0.075 \mathrm{Ta})$ sample. Notably, few reports on lead-free dielectrics can obtain a high $\eta(>80 \%)$ and large $W_{\text {rec }}\left(>2 \mathrm{~J} \mathrm{~cm}^{-3}\right)$ simultaneously under $20 \mathrm{kV} \mathrm{mm}^{-1}$. The NN-BST-0.075Ta sample has a remarkable promise in energy storage dielectric capacitors.

\section{Experimental Procedure}

A novel $0.88 \mathrm{Na}\left(\mathrm{Nb}_{1}-\mathrm{Ta}_{x}\right) \mathrm{O}_{3}-0.12 \mathrm{Bi}_{0.2} \mathrm{Sr}_{0.7} \mathrm{TiO}_{3}(\mathrm{NN}-\mathrm{BST}-x \mathrm{Ta}, x=0,0.025,0.050$, and 0.075$)$ ceramics were fabricated by a conventional solid phase method by using $\mathrm{Nb}_{2} \mathrm{O}_{5}(>99.5 \%), \mathrm{Na}_{2} \mathrm{CO}_{3}(>99.5 \%)$, $\mathrm{Ta}_{2} \mathrm{O}_{5}(>99.9 \%), \mathrm{SrCO}_{3}(>99.5 \%), \mathrm{Bi}_{2} \mathrm{O}_{3}(>99.5 \%)$, and $\mathrm{TiO}_{2}(>99.5 \%)$ powders. Dry raw powders were weighed using the stoichiometric ratio of NN-BST- $x$ Ta and subjected to wet-milling for $36 \mathrm{~h}$ in a teflon jar with isopropanol. Dry mixed powders were calcined at $950^{\circ} \mathrm{C}$ for $2 \mathrm{~h}$ and remixed for $10 \mathrm{~h}$ to obtain 
NN-BST- $x$ Ta as-calcined powders. The refined powder was uniaxially pressed into disk-shaped samples with a thickness of about $1 \mathrm{~mm}$ and a diameter of $10 \mathrm{~mm}$. The disk-shaped samples were sintered at $1160^{\circ} \mathrm{C}$ for $3 \mathrm{~h}$ in an air atmosphere to obtain high density. Discs were bedded in the same composition of as-calcined powders to resist the volatilization loss of sodium and bismuth. Sintered disk-shaped samples were ground and polished to obtain a thickness of $0.1 \mathrm{~mm}$ and measure the electrical performance. The silver electrode with diameter of $0.5 \mathrm{~mm}$ was coated in the middle of the polished disc surface by using the screen-printing method and heated at $550^{\circ} \mathrm{C}$.

Field-emission scanning electron microscope (SEM) was used to examine the surface morphology of samples. The crystal structures of NN-BST- $x$ Ta ceramic samples were performed through X-ray diffraction (XRD). The dielectric constant $\varepsilon_{r}$ - temperature $(T)$ and dielectric loss ( $\left.\tan \delta\right)$-temperature $(T)$ curves were tested by an LCR meter at a heating speed of $120^{\circ} \mathrm{Ch}^{-1}$. Polarization $(P)$-electric field $(E)$ curves were characterized using an ferroelectric tester under $10 \mathrm{~Hz}$ at various temperatures. All specimens were submerged in silicone oil to prevent surface flash over.

\section{Results And Discussion}

The XRD analysis of NN-BST- $x$ Ta ceramics were presented Fig. 1(a). All the ceramics reveal perfect perovskite structure. No other impuritiesare contained. It was suggesting that $\mathrm{Ta}^{5+}$ are dissolved in the NN-BST ceramic lattice and form a uniform perovskite solid solution. The enlarged XRD diffraction patterns in the range of $31.5^{\circ}-46.8^{\circ}$ (Fig. 1(b)) further present variations in (110) and (200) reflection peaks. The (110) and (200) diffraction peaks are not split, which indicates that NN-BST- $x$ Ta ceramics belong to the pseudo-cubic phase. As $x$ increases from 0 to 0.075 , the positions of (110) and (200) diffraction peaks remain unchanged, indicating that the lattice volume has not changed. This phenomenon occurs because the radii of $\mathrm{Ta}^{5+}(0.64 \AA \mathrm{AN}=6)$ and $\mathrm{Nb}^{5+}(0.64 \AA, \mathrm{CN}=6)[26,40]$.

The SEM images of NN-BST- $x$ Ta ceramics were exhibited in Figs. 2(a)-(d). As can be seen from the figures, NN-BST- $x$ Ta ceramics are sintered compactly. We used a linear interception method by Nano Measurer software to calculate the average grain size of NN-BST $-x$ Ta. Results are displayed in Figs. $2(e)-2(h)$. The average grain sizes of NN-BST- $x$ Ta are $1.95,1.72,1.63$, and $1.34 \mu \mathrm{m}$ at $x=0,0.025$, 0.050 , and 0.075 , respectively. The average grain size decreases with the increase of Ta content, which is caused by the low ion mobility of $\mathrm{Ta}[26,40]$. NN-BST-0.075Ta ceramics have a dense microstructure and small grains that may be responsible for increasing $W_{\text {rec }}$ and $E_{\mathrm{b}}$.

Figure 3 shows the $\varepsilon_{\mathrm{r}}-T$ and tan $\delta-T$ curves of NN-BST-xTa ceramics at $1,10,100$, and $1000 \mathrm{kHz}$ frequencies. The dielectric peaks of $x=0$ and 0.025 components are evident at $160^{\circ} \mathrm{C}$, corresponding to the antiferroelectric $\mathrm{P}$ to $\mathrm{R}$ phase transition temperature $\left(T_{\mathrm{P}-\mathrm{R}}\right)$. In addition, at $x=0-0.05, \varepsilon_{r}$ at RT increases significantly and decreases with further increase in $x$. It can be noted that the P-R phase transition peak for $x=0.05$ sample. However, the $\varepsilon_{r}$ at RT is higher than that for samples with $x=0$ and 0.025 , which shows that the $\varepsilon_{r}$ of $x=0.05$ sample is affected by the antiferroelectric $\mathrm{R}$ phase. In addition, 
due to the thermal hysteresis of antiferroelectric $\mathrm{P}-\mathrm{R}$ phase transition during heating, antiferroelectric $\mathrm{P}$ phases are few. When $x=0.075$, the the large $\varepsilon_{r}$ at RT and disappearing dielectric peak $T_{\mathrm{P}-\mathrm{R}}$ at RT indicate that the sample should consist of the antiferroelectric $\mathrm{R}$ phase. Thw similar result has been found in other NN-based relaxor AFEs [25, 29, 41-43].

Figure 4(a) shows the dielectric performance of undoped NN-BST- $x$ Ta ceramics at the temperature range of $-170^{\circ} \mathrm{C}$ to $100^{\circ} \mathrm{C}$. NN-BST-0.075Ta has evident dielectric dispersion and small frequency shift at high temperature. Thus, NN-BST-0.075Ta ceramics has class relaxor characteristics. This relaxor behavior is associated with the different polarizability of perovskite B-site ions. The polarizability of $\mathrm{Nb}^{5+}$ $\left(3.10 \AA^{3}\right)$ is higher than that of $\mathrm{Ta}^{5+}\left(2.82 \AA^{3}\right)$. This phenomenon leads to disordered B-site and random electric field. Therefore, the long-distance driving dipoles are weakened $[25,29]$. The $\varepsilon_{\mathrm{r}}$ and $\tan \delta$ as functions of frequency are shown in Fig. 4(b). The $\varepsilon_{\mathrm{r}}$ and $\tan \delta$ almost remain at the same level at testing frequencies. The dielectric performance shows outstanding frequency stability and is beneficial to the practical application of pulse power transistor. These results are related to the large $P$ and high $E_{\mathrm{b}}[44-$ 48].

The unipolar curves of $P-E$ tested under different electric fields under $10 \mathrm{~Hz}$ for NN-BST- $x$ Ta ceramics are displayed in Fig. 4. Figures 5(a) and (b) present that $x=0$ and 0.025 samples have stable antiferroelectricity. $P_{\mathrm{m}}$ increases when the $E$ is more than $12 \mathrm{kV} \mathrm{mm}^{-1}$, indicating that evident AFE-FE phase transition occurs. For $0.025<x \leq 0.075$ samples, increasing Ta content gradually results in slender $P$ curve. $P$ properties show stable relaxor characteristics, resulting in increased $E_{\mathrm{b}}$ (Figs. $5(\mathrm{c})-5(\mathrm{~d})$ ). This result is because the polarizability of $\mathrm{Ta}^{5+}$ is lower than that of $\mathrm{Nb}^{5+}$, which leads to decreased sensitivity of B-site cations to the $E$ [26]. In addition, $P_{\mathrm{m}}$ increases with increasing of $E$, and the $E$ of the AFE-FE phase transition is getting blurry. Above results are consistent with the dielectric performance.

Figures 6(a)-(c) compare the curves of $P-E, P_{\mathrm{r}}, P_{\mathrm{m}}$, and energy storage properties of NN-BST- $x$ Ta ceramic samples at a low $E\left(15 \mathrm{kV} \mathrm{mm}^{-1}\right)$. NN-BST-0.025Ta and NN-BST have relatively stable antiferroelectric properties and large $P_{\mathrm{r}}\left(25.2\right.$ and $19.9 \mu \mathrm{C} \mathrm{cm}^{-2}$, respectively) and $P_{\mathrm{m}}$ (53.4 and $44.1 \mu \mathrm{C}$ $\mathrm{cm}^{-2}$, respectively). With increasing Ta content, $P_{\mathrm{m}}$ decreases gradually, and $P_{\mathrm{r}}$ decreases rapidly. Zhang et al. [37] studied the $\mathrm{NN}-x \mathrm{Bi}_{1 / 2} \mathrm{Na}_{1 / 2} \mathrm{TiO}_{3}$ (NN- $x \mathrm{BNT}$ ) system and observed similar results. BNT (24 $\mathrm{mol} . \%$ ) is dissolved in $\mathrm{NN}$, and a kind of antiferroelectric material with relaxor characteristics is obtained. In addition, larger nanodomains $(30-50 \mathrm{~nm})$ than PNAs are observed in the material. As mentioned previously, the dopant of the perovskite B-site by Ta results in a local random field, weakening the longrange driving dipole and enhancing the dielectric relaxation. Despite the decreases in $P_{\mathrm{m}}, W_{\text {rec }}$ increases when $0.025 \leq x \leq 0.075$ due to the $P-E$ curve becomes slender and long, thereby broadening the integral area and increasing $W_{\text {rec }}$. Such changes in $P-E$ curves caused by the transition from the antiferroelectric $P$ phase to antiferroelectric $R$ phase are helpful to improve the energy storage performance [49-52]. Subsequently, the $W_{\text {rec }}$ and $\eta$ of NN-BST- $x$ Ta ceramics are compared with several representative leadfree ceramics for energy storage reported recently at low $E$ (Fig. 6(d)) [15, 16, 26, 38, 41-43]. Interestingly, 
$\mathrm{NN}-\mathrm{BST}-0.075 \mathrm{Ta}$ ceramics show a large $W_{\text {rec }}$ of $2.16 \mathrm{~J} \mathrm{~cm}^{-3}$ and high $\eta$ of $80.7 \%$ at $15 \mathrm{kV} \mathrm{mm}^{-1}$, which are larger than those of other lead-free ceramics at a relatively low electric field.

Considering its practical application, temperature dependence is one of the important indices in the design of dielectric capacitor. Figure 7 displays the (a) unipolar $P-E$ curves, (b) $W_{\text {rec }}$, and $\eta$ of NN-BST$0.075 \mathrm{Ta}$ ceramics as a function of temperature under $15 \mathrm{kV} \mathrm{mm}^{-1}$. The unipolar $P-E$ curve displays an excellent temperature stability, which may be due to the stable R phase coexisting in NN-BST-0.075Ta over a wide range of temperature, as displayed in Fig. 7(a),. The $W_{\text {rec }}$ and $\eta$ vary from $1.98 \mathrm{~J} \mathrm{~cm}^{-3}$ and $80.7 \%$, respectively, to $2.2 \mathrm{~J} \mathrm{~cm}^{-3}$ and $85.8 \%$, respectively, at $25^{\circ} \mathrm{C}-125^{\circ} \mathrm{C}$ (Fig. $7(\mathrm{~b})$ ). The variations in $W_{\text {rec }}$ and $\eta$ are less than $11.1 \%$ and $6.3 \%$, respectively. The good temperature stability of NN-BST0.075Ta indicates its potential as lead-free relaxor AFE material for use in temperature-stable pulse capacitor.

\section{Conclusion}

A novel Ta-doped NN-BST dielectric ceramics with a pure perovskite phase is successfully synthesized by a traditional solid state reaction route. The effect of $\mathrm{Ta}^{5+}$ in the perovskite B-site increases the relaxation of the material, thus improving $E_{\mathrm{b}}$ and decreasing $P_{\mathrm{r}}$. Dielectric and ferroelectric performances reveal that the NN-BST-0.075Ta ceramics belong to relaxor AFEs. Therefore, a large recoverable $W_{\text {rec }}$ of $2.16 \mathrm{~J} \mathrm{~cm}^{-3}$ and $\eta$ of $80.7 \%$ at a low electric field of $15 \mathrm{kV} \mathrm{mm}^{-1}$ are achieved in NN-BST-0.075Ta ceramics due to improved relaxation property. NN-BST-0.075Ta ceramics also exhibit excellent energy storage temperature stability. These excellent properties in NN-BST-0.075Ta relaxor AFE ceramics indicate its potential as a candidate in future dielectric capacitors.

\section{Declarations}

\section{Acknowledgments}

The authors acknowledge the supports of the National Natural Science Foundation of China (Grant No. 51902111), the State Key Laboratory of Advanced Materials and Electronic Components (No. FHR-JS202011007), the Key Research Platform and Program in Universities of Department of Education of Guangdong Province (No. 2020GCZX003). P. F. also thanks to the projects supported by Guangdong HUST Industrial Technology Research Institute, Guangdong Provincial Key Laboratory of Digital Manufacturing Equipment (2020B1212060014), and DongGuan Innovative Research Team Program (2020607101007).

\section{References}

1. Li Q, Chen L, Gadinski MR et al (2015) Flexible high-temperature dielectric materials from polymer nanocomposites. Nature 523:576-579 
2. Hao X (2013) A review on the dielectric materials for high energy-storage application. J Adv Dielect 3:1330001

3. Hu P, Shen Y, Guan Y et al (2014) Topological-Structure Modulated Polymer Nanocomposites Exhibiting Highly Enhanced Dielectric Strength and Energy Density. Adv Funct Mater 24:3172-3178

4. Zhang H, Marwat MA, Xie B et al (2020) Polymer matrix nanocomposites with 1D inorganic nanofillers for energy storage capacitors. ACS Appl Mater Int 12:1-37

5. Yao Z, Song Z, Hao H et al (2017) Homogeneous/Inhomogeneous-Structured Dielectrics and their Energy-Storage Performances. Adv Mater 29:1601727

6. Palneedi H, Peddigari M, Hwang GT et al (2018) High-Performance Dielectric Ceramic Films for Energy Storage Capacitors: Progress and Outlook. Adv Funct Mater 28:1803665

7. Pan Z, Yao L, Zhai J et al (2018) Interfacial Coupling Effect in Organic/Inorganic Nanocomposites with High Energy Density. Adv Mater 30:1705662

8. Li Q, Yao FZ, Liu Y et al (2018) High-Temperature Dielectric Materials for Electrical Energy Storage. Annu Rev Mater Res 48:3.1-3.25

9. Li F, Zhai J, Shen B et al (2018) Recent progress of ecofriendly perovskite-type dielectric ceramics for energy storage applications. J Adv Dielect 8:1830005

10. Yang L, Kong X, Li F et al (2019) Perovskite lead-free dielectrics for energy storage applications. Prog Mater Sci 102:72-108

11. Zou K, Dan Y, Xu H et al (2019) Recent advances in lead-free dielectric materials for energy storage. Mater Res Bull 113:190-201

12. Chao M, Liu L, Zeng M et al (2018) High discharge efficiency of $(\mathrm{Sr}, \mathrm{Pb}, \mathrm{Bi}) \mathrm{TiO}_{3}$ relaxor ceramics for energy-storage application. Appl Phys Lett 112:203903

13. Yang $H$, Yan F, Lin $Y$ et al (2017) Enhanced recoverable energy storage density and high efficiency of $\mathrm{SrTiO}_{3}$-based lead-free ceramics. Appl Phys Lett 111:253903

14. Shao T, Du H, Ma H et al (2017) Potassium-sodium niobate based lead-free ceramics: novel electrical energy storage materials. J Mater Chem A 5:554

15. Li WB, Zhou D, Pang LX (2017) Enhanced energy storage density by inducing defect dipoles in lead free relaxor ferroelectric $\mathrm{BaTiO}_{3}$-based ceramics. Appl Phys Lett 110:132902

16. Wang G, Li J, Zhang X et al (2019) Ultrahigh energy storage density lead-free multilayers by controlled electrical homogeneity. Energy Environ Sci 12:582-588

17. Fan P, Zhang ST, Xu J et al (2020) Relaxor/antiferroelectric composites: a solution to achieve high energy storage performance in lead-free dielectric ceramics. J Mater Chem C 8:5681-5691

18. Qi H, Zuo R (2019) Linear-like lead-free relaxor antiferroelectric $\left(\mathrm{Bi}_{0.5} \mathrm{Na}_{0.5}\right) \mathrm{TiO}_{3}-\mathrm{NaNbO}_{3}$ with giant energy-storage density/efficiency and super stability against temperature and frequency. J Mater Chem A 7:3971

19. Yin J, Zhang Y, Lv X et al (2018) Ultrahigh energy-storage potential under low electric field in bismuth sodium titanate-based perovskite ferroelectrics. J Mater Chem A 6:9823 
20. Li J, Shen Z, Chen X et al (2020) Grain-orientation-engineered multilayer ceramic capacitors for energy storage applications. Nature Mater 19:999-1005

21. Chen M, Yao X, Zhang L (2001) Lead lanthanum zirconate stannate titanate based antiferroelectric to ferroelectric phase switching multilayer ceramic actuators. Ferroelecrrics 263:119424

22. Liu Z, Lu T, Ye J et al (2018) Antiferroelectrics for Energy Storage Applications: a Review. Adv Mater Technol 3:1800111

23. Chen L, Sun N, Li Y et al (2018) Multifunctional antiferroelectric MLCC with high-energy storage properties and large field-induced strain. J Am Ceram Soc 101:2313-2320

24. Liu P, Fan B, Yang G et al (2019) High energy density at high temperature in PLZST antiferroelectric ceramics. J Mater Chem C 7:4587-4594

25. Zhuo F, LiQ, Zhou Y et al (2018) Large field-induced strain, giant strain memory effect, and high thermal stability energy storage in $(\mathrm{Pb}, \mathrm{La})(\mathrm{Zr}, \mathrm{Sn}, \mathrm{Ti}) \mathrm{O}_{3}$ antiferroelectric single crystal. Acta Mater 148:28-37

26. Zhao L, Liu Q, Gao J et al. Lead-Free Antiferroelectric Silver Niobate Tantalate with High Energy Storage Performance, Adv Mater 2017, 1701824

27. Lu Z, Bao W, Wang G et al (2021) Mechanism of enhanced energy storage density in $\mathrm{AgNbO}_{3}$-based lead-free antiferroelectrics. Nano Energy 79:105423

28. Han K, Luo N, Mao S et al (2019) Ultrahigh energy-storage density in A-/B-site codoped $\mathrm{AgNbO}_{3}$ leadfree antiferroelectric ceramics: insight into the origin of antiferroelectricity. J Mater Chem A 7:26293

29. Pang F, Chen X, Sun C et al (2020) Ultrahigh Energy Storage Characteristics of Sodium NiobateBased Ceramics by Introducing a Local Random Field. ACS Sustainable Chem Eng 8:14985-14995

30. Luo N, Han K, Zhuo F et al (2019) Aliovalent A-site engineered $\mathrm{AgNbO}_{3}$ lead-free antiferroelectric ceramics toward superior energy storage density. J Mater Chem A 7:14118-14128

31. Qi H, Zuo R, Xie A et al (2019) Ultrahigh Energy-Storage Density in $\mathrm{NaNbO}_{3}$-Based Lead-Free Relaxor Antiferroelectric Ceramics with Nanoscale Domains. Adv Funct Mater 29:1903877

32. Yang $D$, Gao J, Shu L et al (2020) Lead-free antiferroelectric niobates $\mathrm{AgNbO}_{3}$ and $\mathrm{NaNbO}_{3}$ for energy storage applications. J Mater Chem A 8:23724

33. Guo H, Shimizu H, Mizuno Y et al (2015) Domain configuration changes under electric field-induced antiferroelectric-ferroelectric phase transitions in $\mathrm{NaNbO}_{3}$-based ceramics. J Appl Phys 118:054102

34. Zuo R, Fu J, Qi H (2018) Stable antiferroelectricity with incompletely reversible phase transition and low volume-strain contribution in $\mathrm{BaZrO}_{3}$ and $\mathrm{CaZrO}_{3}$ substituted $\mathrm{NaNbO}_{3}$ ceramics. Acta Mater 161:352-359

35. Tan X, Xu Z, Liu Z et al (2018) Double hysteresis loops at room temperature in $\mathrm{NaNbO}_{3}$-based leadfree antiferroelectric ceramics. Mater Res Lett 6:159-164

36. Ye J, Wang G, Chen $X$ et al (2019) Enhanced antiferroelectricity and double hysteresis loop observed in lead-free (1-x) $\mathrm{NaNbO}_{3}-\mathrm{CaSnO}_{3}$ ceramics. Appl Phys Lett 114:122901 
37. Qi H, Zuo R, Xie A et al (2019) Excellent energy-storage properties of $\mathrm{NaNbO}_{3}$-based lead-free antiferroelectric orthorhombic P-phase (Pbma) ceramics with repeatable double polarization-field loops. J Euro Ceram Soc 39:3703-3709

38. Qi H, Zuo R, Xie A et al (2019) Ultrahigh energy-storage density in $\mathrm{NaNbO}_{3}$-based lead-free relaxor antiferroelectric ceramics with nanoscale domains. Adv Funct Mater 29:1903877

39. Wang G, Lu Z, Li Y et al (2021) Electroceramics for High-Energy Density Capacitors: Current Status and Future Perspectives. Chem Rev 121:6124-6172

40. Shi J, Chen X, Li X et al (2020) Realizing ultrahigh recoverable energy densityand superior chargedischarge performance in $\mathrm{NaNbO}_{3}$-based lead-free ceramics via a local random field strategy. $\mathrm{J}$ Mater Chem C 8:3784

41. Xie A, Qi H, Zuo R (2020) Achieving Remarkable Amplification of Energy-Storage Density in Two-Step Sintered $\mathrm{NaNbO}_{3}-\mathrm{SrTiO}_{3}$ Antiferroelectric Capacitors through Dual Adjustment of Local Heterogeneity and Grain Scale. ACS Appl Mater Interfaces 12:19467-19475

42. Wei T, Liu K, Fan $\mathrm{P}$ et al (2021) Novel $\mathrm{NaNbO}_{3}-\mathrm{Sr}_{0.7} \mathrm{Bi}_{0.2} \mathrm{TiO}_{3}$ lead-free dielectric ceramics with excellent energy storage properties. Ceram Int 47:3713-3719

43. Tian A, Zuo R, Qi H et al (2020) Large energy-storage density in transition-metal oxide modified $\mathrm{NaNbO}_{3}-\mathrm{Bi}\left(\mathrm{Mg}_{0.5} \mathrm{Ti}_{0.5}\right) \mathrm{O}_{3}$ lead-free ceramics through regulating the antiferroelectric phase structure. J Mater Chem A 8:8352-8359

44. Shi R, Pu Y, Wang W et al (2020) A novel lead-free $\mathrm{NaNbO}_{3}-\mathrm{Bi}\left(\mathrm{Zn}_{0.5} \mathrm{Ti}_{0.5}\right) \mathrm{O}_{3}$ ceramics system for energy storage application with excellent stability. J Alloy Compd 815:152356

45. Chen J, Qi H, Zuo R (2020) Realizing Stable Relaxor Antiferroelectric and Superior Energy Storage Properties in $\left(\mathrm{Na}_{1}-x / 2 \mathrm{La}_{x / 2}\right)\left(\mathrm{Nb}_{1}-\mathrm{Ti}_{x}\right) \mathrm{O}_{3}$ Lead-Free Ceramics through A/B-Site Complex Substitution. ACS Appl Mater Interfaces 12:32871-32879

46. Pang F, Chen X, Sun C et al (2020) Ultrahigh Energy Storage Characteristics of Sodium NiobateBased Ceramics by Introducing a Local Random Field. ACS Sustainable Chem Eng 8:14985-14995

47. Chen $\mathrm{H}$, Chen $\mathrm{X}$, Shi $\mathrm{J}$ et al (2020) Achieving ultrahigh energy storage density in $\mathrm{NaNbO}_{3}{ }^{-}$ $\mathrm{Bi}\left(\mathrm{Ni}_{0.5} \mathrm{Zr}_{0.5}\right) \mathrm{O}_{3}$ solid solution by enhancing the breakdown electric field. Ceram Int 46:28407-28413

48. Zhang MH, Hadaeghi N, Egert S et al (2021) Design of Lead-Free Antiferroelectric (1- $x) \mathrm{NaNbO}_{3^{-}}$

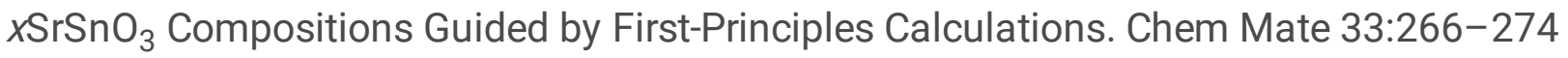

49. Ye J, Wang G, Chen $X$ et al (2021) Effect of rare-earth doping on the dielectric property and polarization behavior of antiferroelectric sodium niobate-based ceramics. J Materiomics 7:339-346

50. Sun C, Chen X, Shi J et al (2021) Simultaneously with large energy density and high efficiency achieved in $\mathrm{NaNbO}_{3}$-based relaxor ferroelectric ceramics. J Euro Ceram Soc 41:1891-1903

51. Yang L, Kong X, Cheng $Z$ et al (2021) Enhanced energy density and electric cycling reliability via $\mathrm{MnO}_{2}$ modification in sodium niobate-based relaxor dielectric capacitors. J Mater Res 36:1214-1222 
52. Chen $\mathrm{H}$, Shi J, Chen $\mathrm{X}$ et al (2021) Excellent energy storage properties and stability of $\mathrm{NaNbO}_{3}$ $\mathrm{Bi}\left(\mathrm{Mg}_{0.5} \mathrm{Ta}_{0.5}\right) \mathrm{O}_{3}$ ceramics by introducing $\left(\mathrm{B}_{\mathrm{i} 0.5} \mathrm{Na}_{0.5}\right)_{0.7} \mathrm{Sr}_{0.3} \mathrm{TiO}_{3}$. J Mater Chem A 9:4789

Figures

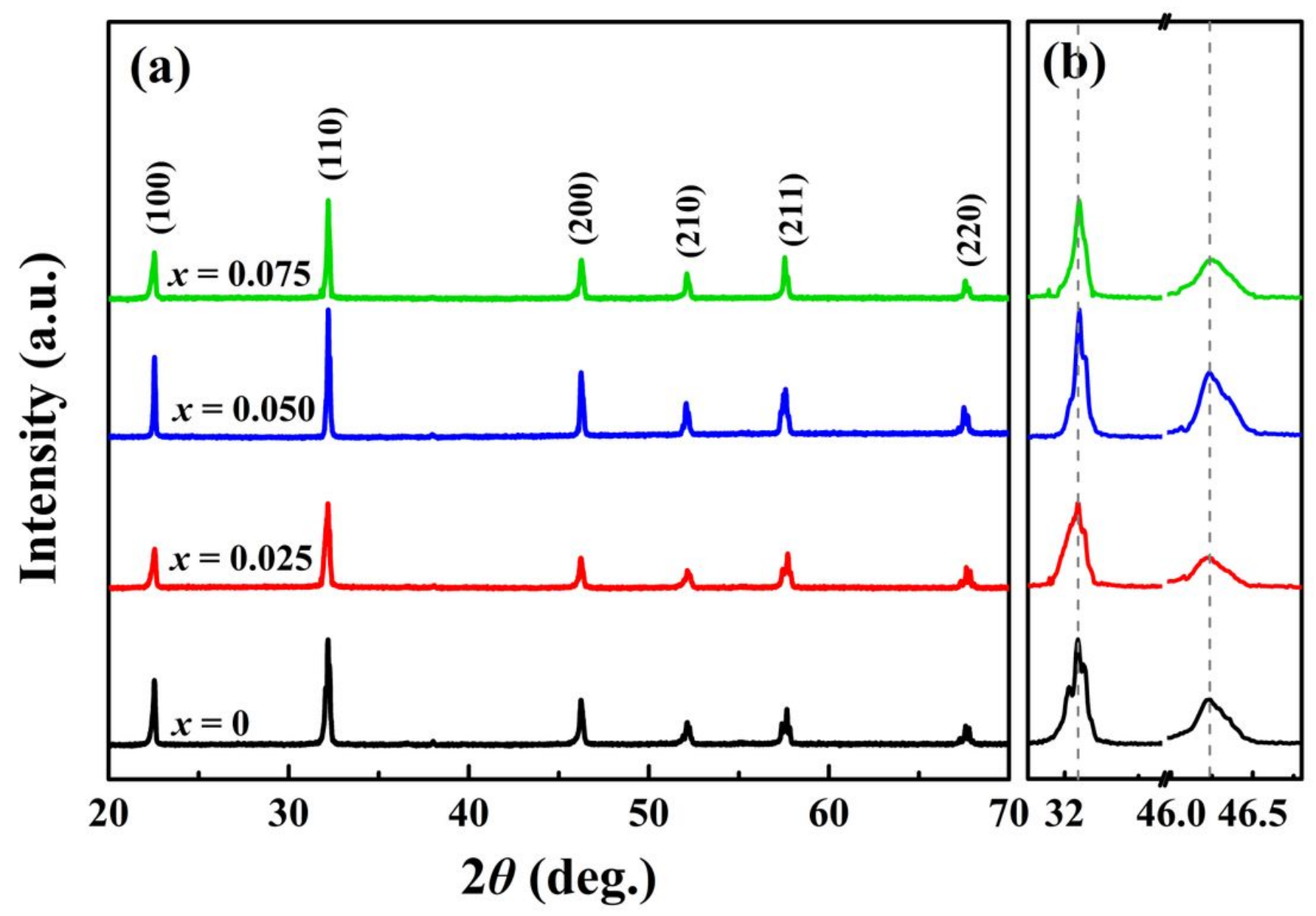

Figure 1

(a) XRD image of NN-BST-xTa ceramics. 

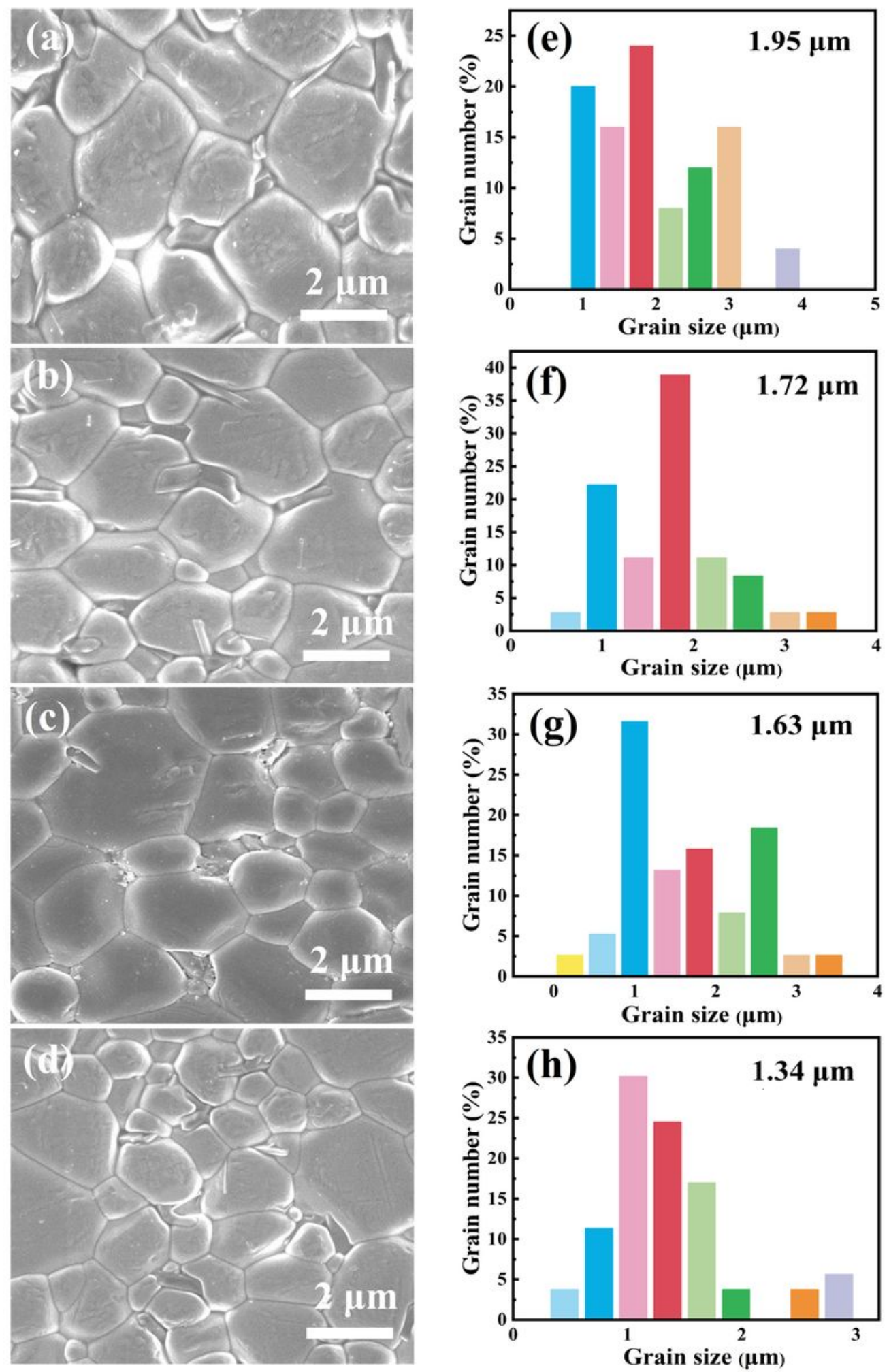

Figure 2

SEM images and average grain sizes of NN-BST-xTa ceramics: (a)-(e) $x=0,(b)-(f) x=0.025,(c)-(g) x=$ 0.050 , and $(\mathrm{d})-(\mathrm{h}) \mathrm{x}=0.075$. 

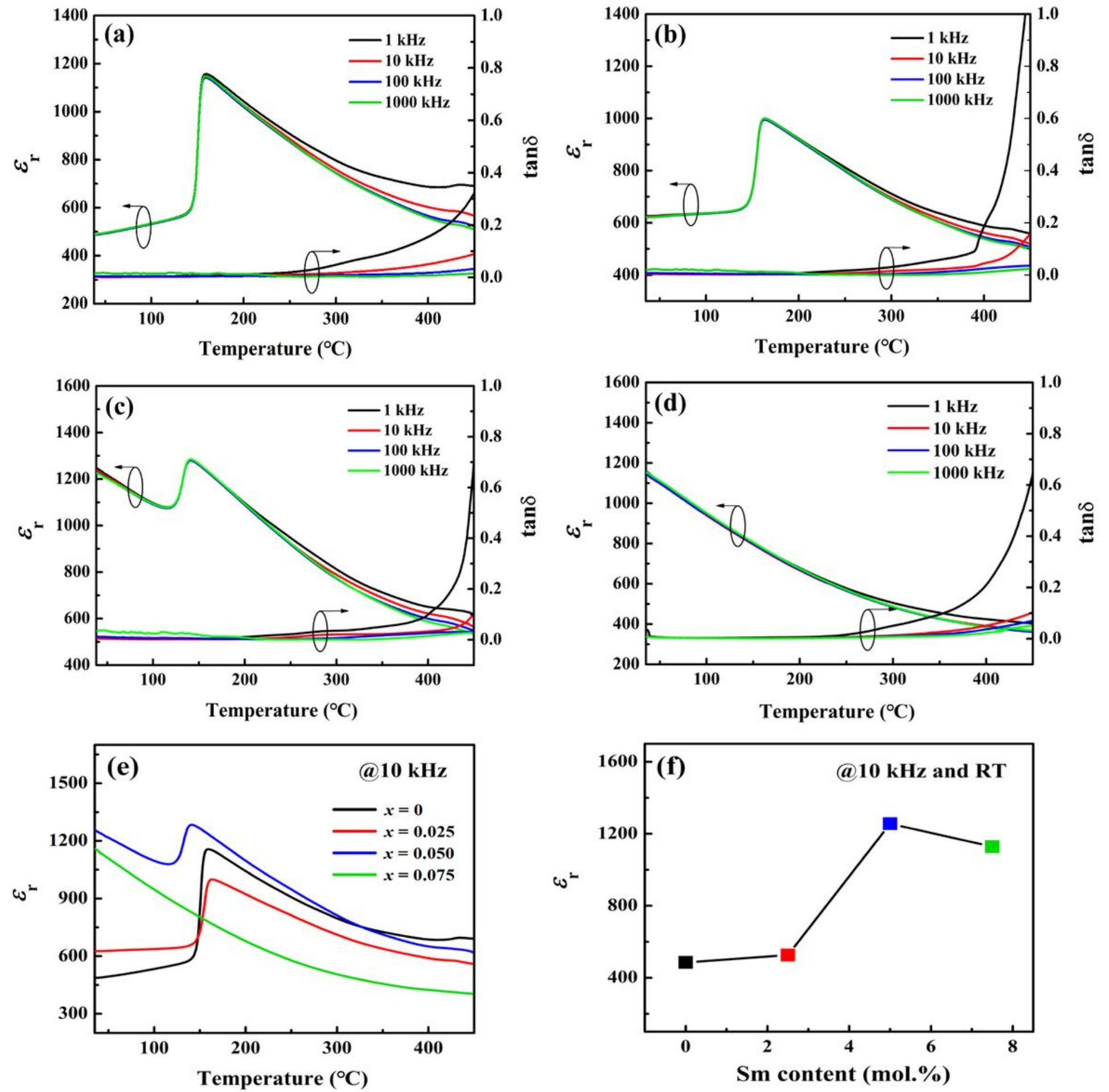

Figure 3

The dielectric constant er)-temperature $(\mathrm{T})$ and loss (tan $\delta)$-temperature $(\mathrm{T})$ curves of NN-BST-xTa ceramics at the temperature range of $25^{\circ} \mathrm{C}$ to $450^{\circ} \mathrm{C}$.: (a) $\mathrm{x}=0$, (b) $\mathrm{x}=0.025$, (c) $\mathrm{x}=0.050$, and (d) $\mathrm{x}=$ 0.075. (e)-(f) Room-temperature er of NN-BST-xTa ceramics with various Ta contents measured at 10 $\mathrm{Hz}$. 

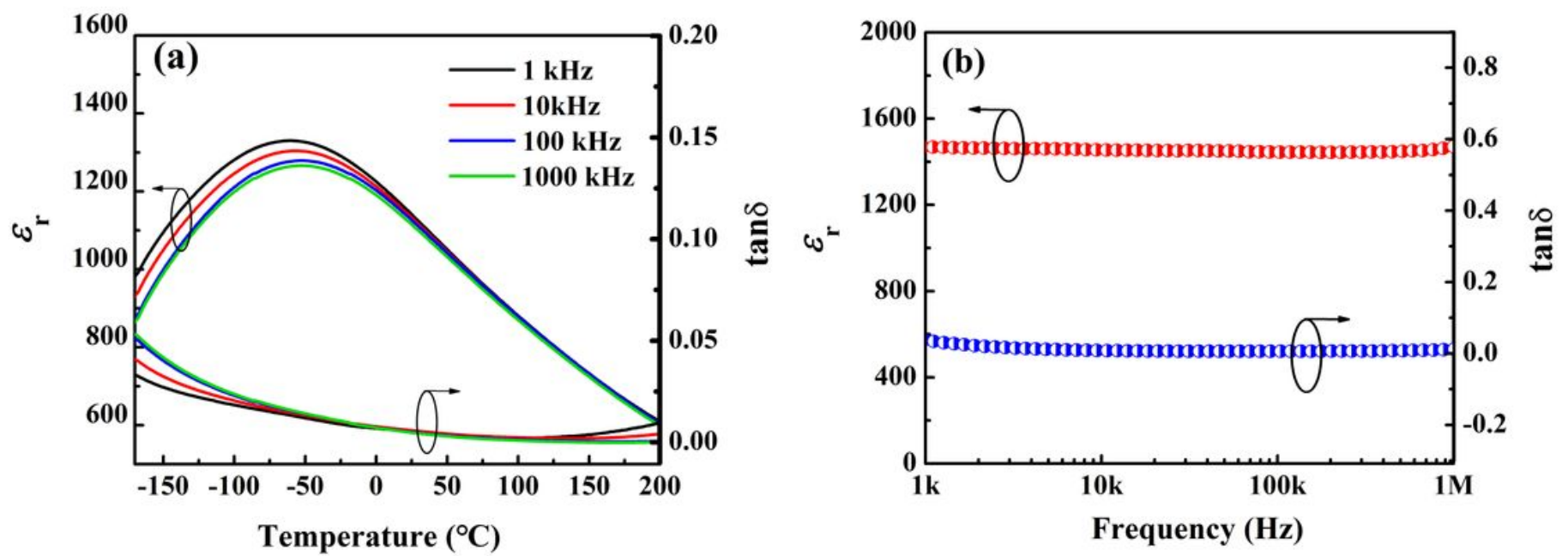

Figure 4

(a) The dielectric constant ( $(\varepsilon r)$-temperature $(\mathrm{T})$ and loss (tan $\delta$ )-temperature $(\mathrm{T})$ curves of NN-BST$0.075 \mathrm{Ta}$ ceramics at the temperature range of $-170^{\circ} \mathrm{C}$ to $100^{\circ} \mathrm{C}$. (b) er and tan $\delta$ of NN-BST- $0.075 \mathrm{Ta}$ ceramics as a function of frequency. 

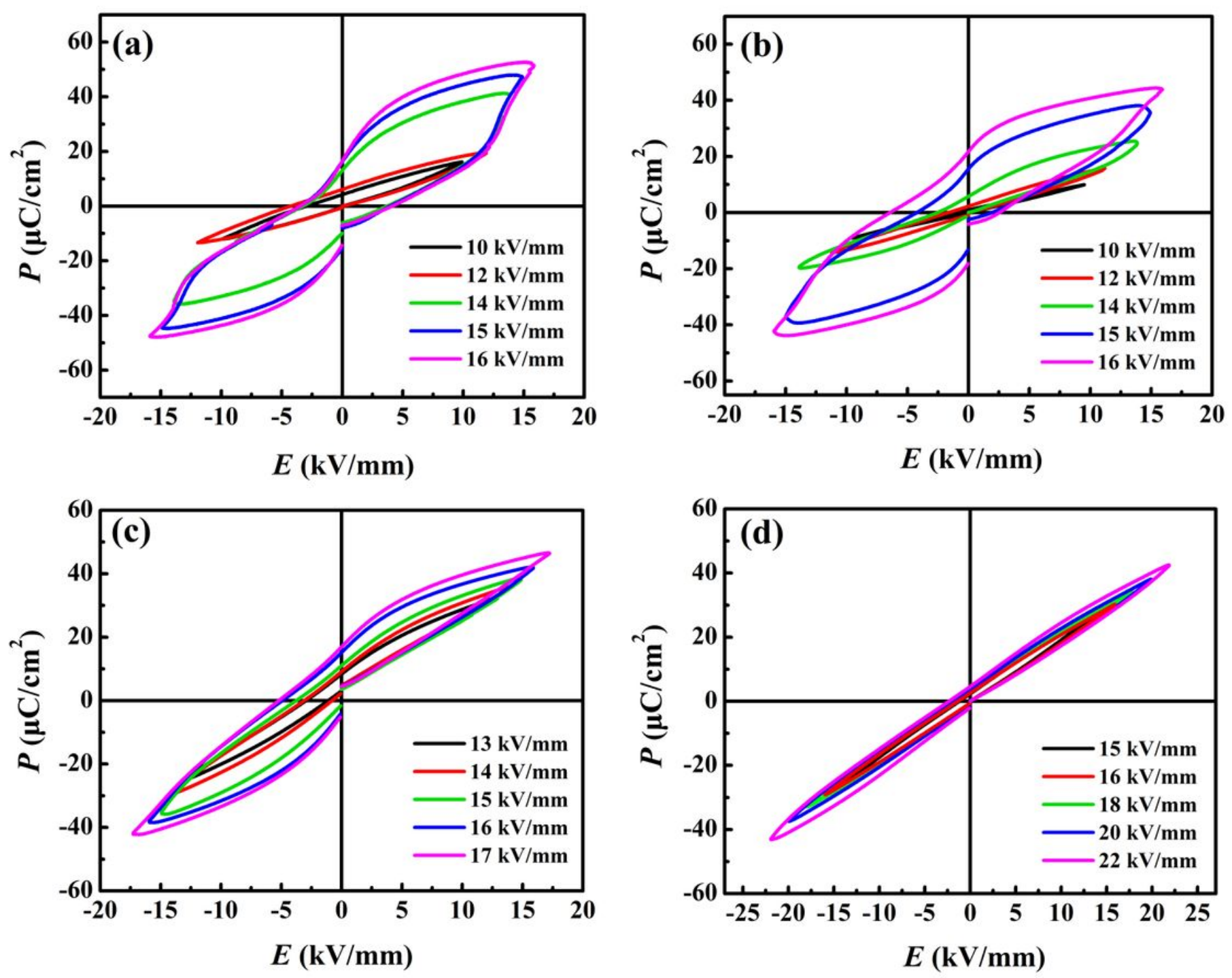

Figure 5

Unipolar P-E curves under different electric fields of NN-BST-xTa samples: (a) $x=0,(b) x=0.025$, (c) $x$ $=0.050$, and $(\mathrm{d}) \mathrm{x}=0.075$. 

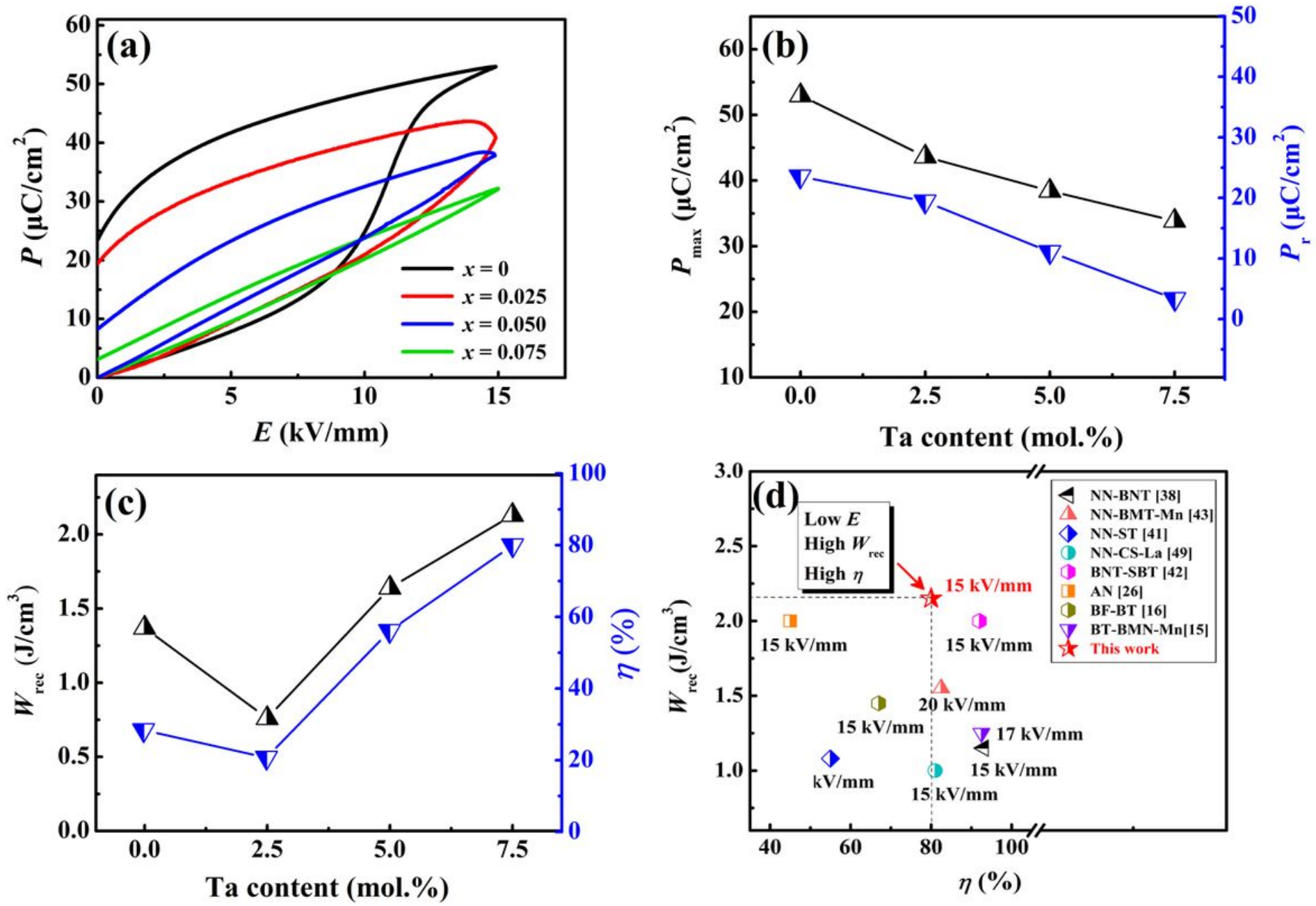

Figure 6

(a) Unipolar P-E curves, (b) Pm, Pr, (c) Wrec, and $\eta$ of NN-BST-xTa ceramics Under different components tested under $15 \mathrm{kV} \mathrm{mm}-1$ at $10 \mathrm{~Hz}$. (d) Comparison of Wrec and $\eta$ between NN-BST$0.075 T$ a ceramics and some recently reported lead-free dielectrics under low electric fields.

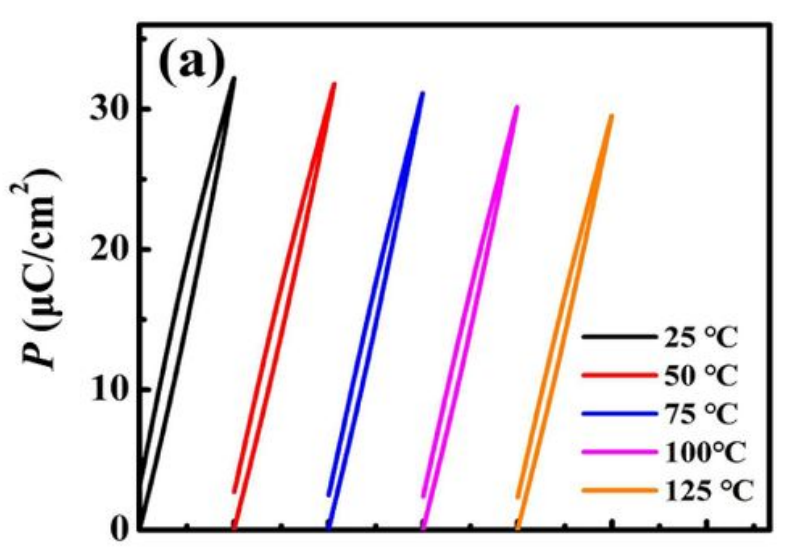

(a) $15 \mathrm{kV} / \mathrm{mm}$

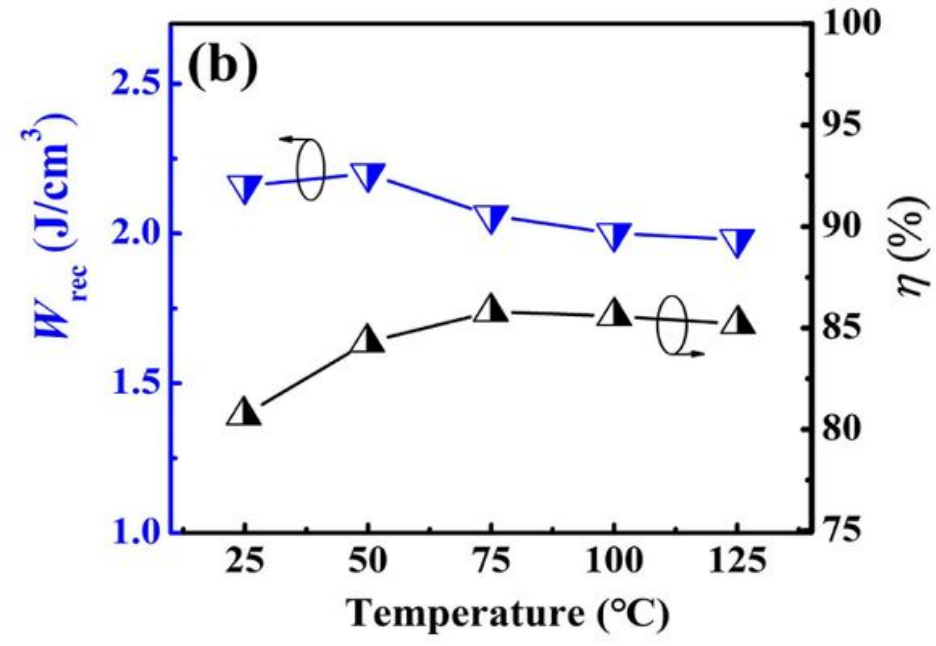


Figure 7

(a) Unipolar P-E curves and (b) corresponding energy storage performance of NN-BST-0.075Ta ceramics at different temperatures under $15 \mathrm{kV} \mathrm{mm}-1$. 